\title{
O Beethoven de DeNora: $o$ contexto está no texto
}

\author{
Marcos Câmara de Castro (USP campus Ribeirão Preto, S.P.) \\ mcamara@usp.br
}

\begin{abstract}
Resumo: Estudo sobre a repercussão do livro de DENORA (1995), e discussão sobre os conceitos que vêm à tona, a partir de uma abordagem sociológica do fenômeno do "gênio criador"; do surgimento do conceito de "música séria"1 em oposição ao entretenimento; das estratégias de ocupação de um determinado campo cultural e suas aplicações em novos contextos. Todos os fatores que elegeram Beethoven são inoperantes num mundo em que novas regras se impõem na produção artística, tanto quanto na produção de mercadorias em geral: essa a principal contribuição do livro, que passou despercebida pela maioria das resenhas publicadas à época de sua publicação. Os esquissos do projeto da música dita "séria" são facilmente detectáveis na obra de Beethoven, em que sua busca de profundidade, em oposição à música leve, atinge novos patamares pari passu com sua posição social como compositor.
\end{abstract}

Palavras-chave: Beethoven; cânone; classicismo vienense; contexto de recepção; música e sociedade; Tia DeNora

\section{DeNora's Beethoven: the context is in the text}

Abstract: Study on the impact of the DENORA's book (1995) and discussion of the concepts that come to light, from a sociological approach to the phenomenon of "creative genius"; the emergence of the concept of "serious music" as opposed to entertainment; strategies of occupation of a particular cultural field and its applications in new contexts. All factors that elected Beethoven are inoperative in a world where new rules are imposed on artistic production, as much as on the production of goods in general: this is the main contribution of this book, which remained unnoticed by most of the reviews published at the time of his publication. The sketches of the music project called "serious" are easily detectable in the work of Beethoven, and in his quest for depth, as opposed to pleasingness as a value, reaches new heights pari passu with his social position as a composer.

Keywords: Beethoven; canon; Viennese Classicism; reception context; music and society, Tia DeNora.

\section{1- Introdução}

Para compreender gosto, talento e valor, e porque alguns compositores se estabelecem como unanimidades clássicas e outros a quem as portas do reconhecimento são fechadas, é preciso pensar sobre a construção social da identidade e seus componentes políticos, pois a história da música não pode ser compreendida apenas pelo discurso musicológico convencional. Ninguém melhor do que Beethoven para ilustrar a construção social do gênio que tem tantos paralelos com os livros sobre Villa-Lobos, de GUÉRIOS (2003) e de FLÉCHET (2004) ou com o trabalho sobre Mozart de ELIAS (1991). Qual o sentido de uma pesquisa assim?
Em primeiro lugar, trata-se do reconhecimento de que os clássicos são produto da ideologia do cânone, que se estabelecia, segundo DeNora, no momento da chegada de Beethoven em Viena, e a análise estrutural é 0 instrumento político de legitimação de um gosto determinado. Gostamos de dizer que o gênio é compreendido a posteriori, ignorando os contextos de recepção e as razões sociais que determinam a eleição de clássicos, como se o panteão fosse imutável e imune a revisões e reconsiderações.

Se a compreensão dos fatores que elegem o cânone contribui para uma renovação da linguagem musical e 
nos permite rever as razões pelas quais este ou aquele compositor sobe ou desce no ranking canônico, nada mais saudável do que mergulhar nos contextos históricos e recontarmos o processo para a época atual, de rupturas estéticas e discursos hegemônicos, e avaliarmos em que medida as estratégias que funcionaram para Beethoven são ainda operantes nos dias atuais.

\section{2- Resenha das resenhas}

Fato significativo, este livro mereceu pelo menos seis resenhas e uma discussão com Charles Rosen, no New York Review of Books, com uma réplica da autora e uma tréplica do crítico/pianista². Dependendo da tendência mais para o texto ou mais para o contexto, certos críticos preferem dizer que "os sociólogos gostam de..."; ou "como os sociólogos gostam de ver" etc, numa tentativa de enfraquecer o discurso inconveniente da sociologia, quando trata de assuntos frequentemente ignorados pelos músicos práticos e mesmo pelos analistas.

De qualquer maneira, como diz HANSON (1997), este livro é endereçado a "estudantes sérios da biografia de Beethoven, bem versados sobre as personalidades e questões relativas ao final do século XVIII e informados sobre as abordagens acadêmicas da história cultural" ${ }^{3}$.

Já KINDERMAN (2000) diz que DeNora oferece seu livro como um corretivo ao conhecimento existente, "onde muito do campo de estudos sobre Beethoven é ocupado pela hagiografia", opondo-se ao hábito de isolar sua obra como única causa de seu reconhecimento". Kinderman também nota que a autora dá pouca atenção à literatura existente em língua alemã ${ }^{4}$.

\section{1 - Knittel}

KNITTEL (2010) lembra "o quanto perdemos ao tratar Beethoven não como uma pessoa mas como Beethoven", e considera "o aspecto mais importante do livro o olhar que a autora dedica ao jovem Beethoven: não como um titã pronto para conquistar Viena, mas como um jovem ambicioso e cauteloso, chegando numa cidade distante, aprendendo cuidadosamente as complexidades de sua sociedade e também como as convenções musicais poderiam ser estendidas, testadas e mesmo rompidas"5.

Ainda segundo Knittel, "examinar Beethoven como um ícone cultural só pode nos levar a duas possibilidades: confirmar o mito ou desacreditá-lo. Fora desses dois propósitos, deixar a partitura um pouco de lado pode nos proporcionar uma distância necessária para escrever uma história crítica"6 .

0 crítico lembra também que "a história da recepção é o estudo sobre quais outras questões influenciaram os críticos a olhar uma peça de uma maneira particular, sendo a música assim um ponto de entrada para se examinar o contexto cultural"7 e, se partimos do pressuposto da transcendência, "perdemos outras possibilidades de ouvir e de escrever a história"8.

\section{2 - Bowen}

0 livro de DeNora faz BOWEN (1998) perguntar-se até que ponto nossa avaliação da grandeza de Beethoven pode ser inserida na história dos vencedores ${ }^{9}$ e o faz questionar também se nossas unidades de valor em música já estariam pré-concebidas, uma vez que "aceitamos a música de Beethoven como modelo"10. E continua: "Um exame dos escritos do passado e do presente revela não apenas os valores aceitos implicitamente, mas também a tendência a comparar todos os compositores subsequentes a Beethoven"11 e que "fazer dele a medida de todas a coisas influencia a maneira como vemos esses outros compositores" 12 .

\begin{abstract}
"É precisamente durante a vida de Beethoven que começam a surgir as novas ideias sobre identidade da obra musical, o cânone musical, a música instrumental, o conteúdo poético e a ideologia da música séria"13. "É tão difícil ouvir com ouvidos de outra cultura quanto fazê-lo com o de outras épocas, e ainda poderiamos reconsiderar as maneiras pelas quais nós aprendemos a ouvir - o que poderia abrir nossos ouvidos para possibilidades adicionais" e esse é o principal legado desse projeto de DeNora ${ }^{14}$.
\end{abstract}

\section{3 - Charles Rosen}

É difícil ler a resenha de ROSEN (1996), e depois a tréplica (1997), sem considerar as páginas 123-124 do livro de DeNora, onde ela diz sobre a análise dele da Hammerklavier: "afirmações desse tipo, que tentam estabelecer mudanças estilísticas na obra de um compositor, são problemáticas de um ponto de vista sociológico porque a análise musical é formulada e somente faz sentido em contextos históricos e culturais específicos"15. 0 que Rosen diz é que "a história da música é uma interação entre o talento individual, pressões sociais e o sistema musical vigente. 0 mais estável desses fatores é, de fato, o sistema musical. Ao ignorá-lo completamente, DeNora vicia toda generalização"16.

$\mathrm{Na}$ resenha propriamente dita, Rosen desaponta-se ao constatar que a autora "não faz qualquer consideração histórica sobre a grandeza em música e nas outras artes", afirmando que as primeiras ocorrências do "gênio temperamental" são de bem antes, e evoca Josquin e Ockeghem para justificar sua assertiva ${ }^{17}$, mas fica claro que, embora atitudes assim já existissem antes, é com Beethoven e a ideologia da música dita "séria" que a excentricidade se torna um valor consciente e socialmente compartilhado.

Rosen lembra que o abismo entre música "trivial" e "séria" foi colocado pelos próprios músicos da época e que a primeira liga de músicos vienenses, formada no início dos 1780, bania os intérpretes de música de dança e que o crescimento da música dita "séria" e não litúrgica foi "o resultado natural do declínio do patrocínio musical pela corte e pela igreja"18 - 0 que está explicado claramente no livro de DeNora.

\section{4 -Anderson}

Anderson contesta equivocadamente ${ }^{19}$ a afirmação de DeNora, na p.14, de que Mozart orquestrou não só 0 Messias mas também três outros oratórios: 
Mozart participava dos concertos de domingo à tarde na casa de van Swieten (onde os participantes cantavam a música coral de Bach, acompanhados por Mozart ao piano), e ele orquestrou quatro oratórios de Händel, sob as instruções de van Swieten para "de um lado agradar ao modismo e de outro mostrar sua sublimidade" (in DEUTSCH, 1965, p.337) ${ }^{20}$.

No catálogo de obras de EINSTEIN (1971, p.500-501), constam: Acis und Galathea (K. 566); Messiah (K. 572); Alexander's feast (K. 591) e Ode to Saint Caecilia (K. 592) - obras que são consideradas oratórios pelo dicionário Grove ${ }^{21}$.

\section{3 - Beethoven e a identidade social}

A divisão entre expert (Kenner) e amador (Liebhaber) já existia na Viena pré-Beethoven, impregnada da noção da grandeza em música. Afirmar seu reconhecimento pelo isolamento das qualidades das obras é contar metade da história. Mesmo em ciência, uma determinada descoberta é socialmente acumulada, às vezes por longos periodos, e a retórica do gênio requer um exame crítico.

Compositor de verdadeiras grandes obras, a posição que Beethoven adquiriu na história não deveria tornar seus contemporâneos "errados" só porque objetaram a seu estilo, e ai vemos como a autoridade estética é produzida e sustentada.

Por outro lado, é preciso também estudar em que medida a lenda "pelas mãos de Haydn", enunciada pelo Barão Waldstein, foi construída sob circunstâncias em que interessava a todos os atores e também aos aristocratas do gosto - recurso de distinção para fazer frente à crescente participação da burguesia na promoção de concertos públicos.

\section{4 - 0 surgimento da cultura da música dita "séria", 1784-1805}

DENORA (p.12-16), conta que por volta de 1789, a sorte de Mozart mudava, quando, após fazer circular por duas semanas uma lista de subscrição, foi forçado a abandonar o plano por ter recebido uma única assinatura. Essa única adesão tinha o nome do Barão Gottfried van Swieten - personagem central na Viena do período e um dos principais artífices da aristocracia do gosto levada a cabo justamente quando o concerto público vivia um declínio temporário na capital austriaca devido à falta de recursos da nobreza. A metáfora culinária, tão habitual hoje, já era comum no discurso musical do século XVIII. De acordo com a noção de Burney a respeito de naturalidade e facilidade como critérios de gosto, numa "estética do amadorismo" (DENORA, p.16) que podemos encontrar um paralelo nas Leis de Platão, em que toda música que não fosse fácil de aprender ou tocar era reprovada ${ }^{22}$. Longe de ser considerada como um fim em si mesma, a música no século XVIII era pensada e feita para entreter, e uma mudança ocorreria no mundo privado dos salões aristocráticos. Reconhecido em sua época como o decano dos patrões musicais, van Swieten - a quem Beethoven dedicou sua I Sinfonia em 1800 - teve um importante papel como inicialmente o único protetor de Beethoven entre os aristocratas.
0 movimento Sturm und Drang (Tempestade e Impulso), dos círculos literários berlinenses, e que coincide com a chegada em Viena de van Swieten, pregava a completa rejeição da disciplina e da tradição e ligavase à espontaneidade. A moderna noção de "gênio" foi articulada primeiramente no norte da Alemanha entre 1770 e 1780, frequentemente em resposta à obra de Shakespeare - vista "menos como teatro do que como poesia e retratos psicológicos" (DENORA, 1995, p.23). Goethe se opunha diretamente à metáfora culinária, considerando vil a noção da composição musical como "um pedaço de bolo feito com ovos, farinha e açúcar", mas "uma verdadeira criação em todo pormenor, e o todo como espírito e atitude" (DENORA, p.23-24).

Até então, a música como veículo de expressão pessoal e emocional era estranha à Viena do período, e van Swieten foi propagador das ideias de "grandeza" e "verdade", que abririam as portas para a hegemonia beethoveniana. Seu entusiasmo pela música dita "séria" tornou-o uma figura chave na promoção da ideologia do cânone na Viena dos anos 1780-90 e considerado por seus contemporâneos como pioneiro das novas convenções do consumo da música nas salas de concerto, nas fronteiras do consumo aristocrático.

Examinando o contexto da vida musical em Viena, entre 1791 e 1810, DeNora (DENORA, p.29-30) verifica que, em comparação com seus contemporâneos (Par, Weigl ou Cimarosa), Mozart, Haydn e Beethoven ocuparam uma excepcional parcela do espaço dos concertos públicos ${ }^{23}$, podem ser considerados verdadeiras "estrelas" musicais do periodo - celebridades sobre as quais as atenções se concentraram, embora a noção de música "séria" fosse só compartilhada pelos antigos aristocratas vienenses e não ainda pela classe média.

\section{5 - Patrocínio musical e mudança social}

A música era então o veículo mais importante através do qual se poderia demonstrar, ganhar (e eventualmente perder) prestígio e status. No final do século XVIII, as fortunas dos aristocratas perderam-se ou se reduziram significativamente, obrigando-os a ser menos exclusivistas com relação ao patrocínio musical e levando os músicos a trabalhar num sistema de eventopor-evento (quasi free-lance style), ao invés de trabalhar full time em uma Hauskapelle ou Hofkapelle. Essa queda econômica da nobreza proporcionou um aumento do público de concerto e de patrocínio da burguesia, que culminaria no controle absoluto da vida musical em meados do século seguinte.

Considerando que uma fonte de prestígio adotada por uma determinada classe social perde logo seu caráter distintivo para as classes imediatamente superiores, assim que as Hauskapellen tornaram-se moda, começaram a ser imitadas pela nobreza inferior que, na falta de recursos, patrocinavam bandas - mais baratas de ser mantidas e bem menos gloriosas do que uma Capela completa. Aqueles que 
não tinham recursos para mantê-la - e nem mesmo uma banda, que era a "Capela do pobre" - podiam se engajar na vida musical através de subscrições aos concertos ou promovendo, e assistindo a, concertos privados.

Por outro lado, na medida em que a corte se retira da competição pela manutenção de uma Hauskapelle, sua principal razão de existir se perde, abrindo, ainda que involuntariamente, espaço para uma participação mais ampla nos negócios musicais. É justamente nesse momento que os músicos começam a deixar a situação de servos para se tornarem profissionais autônomos. Em 1796, 30\% dos participantes em assinaturas já eram da classe média vienense (DENORA, 1995, p.46).

Mesmo com a "democratização" dos concertos privados, os salões permaneciam como espelho social e instrumento de estabilidade, e de modo algum havia fraternização entre nobreza e burguesia cortesã. Se o patrocínio agora não era exclusividade nobre, alguma distinção teria que haver, e é aí que entra a ênfase no "bom gosto" e na "grandeza" como formas de construção de uma nova aristocracia: a aristocracia do gosto.

Um meio de reconstrução da identidade social através de novos meios culturais, a ideologia do cânone encontra sua legitimação nas estratégias analíticas, sob o risco de perderem o lugar de liderança da vida cultural. A velha aristocracia vienense, consciente das implicações dessa mudança, adota a nova ideologia da música "séria" como forma de manter seu status, e considerando decadente o alargamento do público de concertos, como uma poluição social. Isso favoreceu o surgimento de um músico quasi free lance protagonizando a passagem para uma estrutura organizacional que favorecia o estrelato, e cujas celebridades emergiram independentemente de Beethoven.

0 que havia era um terreno fértil para uma grandeza musical qualitativamente diferente e Beethoven tinha uma posição vantajosa quando chegou a Viena com as "costas quentes".

\section{6 - Os recursos sociais de Beethoven}

Num momento em que as conexões aristocráticas eram ainda cruciais para a sobrevivência do músico, Beethoven estava excepcionalmente bem colocado, na medida em que suas composições orientavam-se para um gosto refinado e exclusivo.

Comparado com Dussek (1760-1812), DENORA (p.6162) diz que: "é irônico que Dussek seja lembrado principalmente como um dos contemporâneos menores de Beethoven, mais do que uma provável fonte de inspiração" para o mestre de Bonn, já que Breitkopf e Härtel (principais editores de Beethoven depois de 1802) publicaram obras inteiras de Dussek (elogiado por Haydn) bem antes de publicarem Beethoven.

\section{7 - "Pelas mãos de Haydn": construções narrativas do talento de Beethoven e de seu futuro sucesso}

Sendo nossas avaliações sobre Beethoven feitas em retrospecto, é bom lembrar que o valor dele foi contestado até por Haydn, e o que nos parece hoje axiomático - sua superioridade em relação a seus contemporâneos - era na época apenas uma promessa. Haydn portanto estaria mais para constrangido a contribuir com a história "pelas mãos de Haydn", independentemente do que pensava a respeito. (Neste capítulo, DeNora omite os cinco anos em que Sugismund Neukomm viveu ativamente no Rio de Janeiro, apesar de ter gasto quase toda a página 92 sobre sua carreira).

Haydn, como professor, gozava de uma reputação que fazia com que seus alunos o citassem numa via de mão dupla em que ganhavam status ao mesmo tempo que emprestavam credibilidade ao mestre. Possivelmente por serem "alunos devotados", tornaram-se também contemporâneos menores, já que Beethoven demonstrava claramente sua intenção de superar o mestre, bem protegido por seus aristocratas, enquanto os outros alunos de Haydn permaneciam inteiramente dependentes de seu professor para recomendações e contatos. A ideia da tradição canônica Bach-Handel-Mozart-Haydn, a noção de compositor extraordinário e as novas práticas de comportamento nos concertos construíram uma rota para longe do conceito de compositor como servo (DENORA, p.113).

\section{8 - Beethoven nos salões}

A reputação de Beethoven, construída a partir da acumulação de registros e publicações a seu respeito, construiu sua fama como função do aumento do conhecimento que se tinha a respeito de sua grandeza: lendas e imagens que alimentaram o assunto.

Numa comparação que nos é familiar, a fama de Beethoven na época não foi consequência de sua popularidade, mas fruto das análises que Ihe conferiam recurso para sua confirmação como compositor canônico, da mesma maneira que os arcadistas brasileiros do século XVIII se tornariam a literatura representativa de uma época em que a poesia religiosa devocional não-litúrgica era a prática popular mais conhecida ${ }^{24}$.

DeNora contesta a abordagem sem "contexto histórico e cultural" que Charles Rosen faz da Sonata Hammerklavier, e afirma o quanto nós atribuímos aos ouvidos de 1790 nosso quadro de referências. "Em outras palavras", ela diz, "como eram experimentadas essas peças, não por analistas do século $X X$, mas por membros do concerto vienense e público dos salões", numa perspectiva do contexto de recepção. Até recentemente, ela continua, "havia uma ausência de ligações entre a musicologia e as ciências humanas e essa lacuna vinha ajudando a sustentar uma forma implícita de positivismo naïf da análise e da crítica", isto é, "categorias de análise como historicamente transcendentes" (DENORA, p.125). 
DeNora insiste na importância do contexto de recepção para considerar criticamente as posições musicológicas convencionais, considerando que os significados sociais são apropriados para o discurso analítico, propondo a realização de uma análise mais completa que inclua o texto e o contexto ${ }^{25}$, muito embora tenha sido criticada nas resenhas citadas por sua distância do texto. Ela diz que "qualquer leitura de conteúdo ou significado em música é melhor compreendido sob a forma de política cultural e de afirmações sobre a relação entre status, conteúdo, e estrutura musical (...) e aquilo que pode ter sido dito e as várias identidades imputadas ao texto por seus receptores permanece conspicuamente ausente" (DENORA, p.127).

A grande contribuição deste livro é a proposição de uma teoria e de uma metodologia de estudos da recepção em oposição ao que ela chama de "posição formalista pseudocientífica" (DENORA, p.128), pelo menos admitindo outras vozes que não à do próprio analista: "Formalistas gostam de seu autodenominar 'puramente' técnicos, como se as técnicas de análise pudessem se desenvolver independentes de valores e pressupostos sobre o texto musical e suas relações com fatores sociais e culturais".

Para ilustrar, DENORA (p.129) ${ }^{26}$ cita o estranhamento estampado durante os anos 1790, com relação à obra de Beethoven: 1) textura espessa (thicker textured); 2) escrita pianística menos inclinada a padrões escalares; 3) melodias estruturadas de forma ambígua e menos periódicas; 4) harmonias aventureiras e ambíguas; 5) maior contraste dinâmico com mudanças súbitas e esforzandos mais comuns; 6) composições mais longas do que aquelas de seus predecessores e contemporâneos.

A questão se desloca para o quanto a relação entre a obra de Beethoven e a de seus predecessores ilustres foi construida e politizada. Sob o ponto de vista de seus contemporâneos, sua música "controversa e diferente" (DENORA, p.130) implicava em novo critério de valor. Czerny observa que nos anos 1800 "o público em geral condena completamente a obra de Beethoven" (DENORA, p.131) em favor de Hummel - favorito dos diletantes. E Tomaschek comenta que "a coisa mais importante em composição para ele [Beethoven] parece ser o inusual e o original" (DENORA, p.132-133). Frequentemente, observa DeNora com perspicácia, "a diferença, em condições favoráveis, pode ser construída como novidade e, ainda mesmo, como inovação" (DENORA, p.134) - uma constatação útil para os dias atuais em que se observa a tendência para a redoma dos discursos hegemônicos ${ }^{27}$.

"No começo dos anos 1800, Beethoven foi o primeiro músico a ser conhecido como compositor e não como pianista-compositor" (DENORA, p.134) e o século XIX é palco da bifurcação entre música como entretenimento e como edificação. Nos salões de Lichnowsky, a obra de Beethoven era apresentada de maneira a ser vista e aceita como importante e provida de sentido, longe de uma exposição à recepção aleatória de qualquer ouvinte. Essa é a estratégia que se vê hoje em dia, tanto nos vernissages ${ }^{28}$ quanto nos concertos de música contemporânea.

A música no século XVIII era um meio diplomático e de troca cultural, um pretexto para contatos com a nobreza estrangeira e razão para socialização ao introduzirse um compositor para um público novo e curioso (DENORA, p.141) - o que não é diferente hoje em dia, dentro da multiplicidade de manifestações musicais que os paises divulgam internacionalmente. Beethoven adquiriu a aura de ter alcançado seu sucesso público independentemente, quando na verdade seu êxito se deveu em grande parte às fortes ligações diplomáticas entre seu patrão e figuras chave no estrangeiro.

As contribuições empreendedoras de Beethoven, tanto sociais quanto musicais, impediram que ele fosse um "objeto passivo em torno do qual seus patrões construíram sua moldura de grandeza" (DENORA, p.142). Essa reputação, insiste DeNora, é produto da "interação entre seus próprios esforços, suas circunstâncias sociais, e os esforços de outros" (DENORA, p.143). "Um recurso chave para Beethoven foi a tradicional concepção de privilégio, isto é, que alguns indivíduos (os nobres) são mais dignos que outros" e ele não estava interessado na abolição desse conceito (DENORA, p.143) e evidencia suas pretensões aristocráticas, tema bem explorado por Solomon (a história do van/von) - que é citado com frequência pela autora - e que também é vislumbrado por ELIAS (1994) a respeito de Mozart.

Nunca é demais lembrar da reforma da etiqueta do concerto, estratégia que Beethoven empreendeu em direção a uma solene e ritualística devoção à performance, numa época em que os participantes podiam conversar, andar pelo salão, comer e beber, jogar cartas e outros jogos de azar, e realizar encontros com amantes e cortesãs (DENORA, p.146).

\section{9 - 0 duelo Beethoven-Wölffl: debates estéticos e fronteiras sociais}

Em meados de 1790, ainda não havia nenhuma posição coerente articulada contra Beethoven e suas participações menos convencionais parecem ter ocorrido em suas improvisações, mais do que na obra publicada - bem mais acessível (DENORA, p.148). 0 duelo pianístico era então mais do que um evento "esportivo" e proporcionava um fórum para debates estilísticos e estéticos, numa demarcação ainda evidente entre música dita "séria" e música de entretenimento (para o Kennere para o Liebhaber).

Numa comparação entre Beethoven e Wölffl, redigida na Allgemeine Musicalische Zeitung (AMZ, de propriedade de Breitkopf e Härtel, que passariam a publicar Beethoven), poder-se-ía não apenas admirar, mas também apreciar suas obras. Não só as abordagens pianísticas de ambos eram 
discutidas, mas também as relações entre connoisseur e dilletante eram colocadas em questão. A sinfonia "Heroica" - duas vezes mais longa do que qualquer sinfonia de Mozart ou Haydn - polarizou ainda mais as opiniões, quando foi criticada por "perder-se na anarquia" e por ser "estridente e bizarra" (DENORA, p.160). 0 duelo serviu como veículo através do qual duas redes sociais eram distinguidas: a nobreza e a segunda sociedade, servindo para redefinir seus patrões não só como príncipes da sociedade, mas também como "príncipes do gosto" (DENORA, p.169).

\section{0 - Primeiras campanhas estéticas de Beethoven}

Interessado na reforma do instrumento piano, para que fosse capaz de resistir à sua "energia animal" e projetar seus sentimentos intensos, além de compensar sua progressiva surdez, Beethoven foi protagonista de uma campanha em favor de novas tecnologías de construção do instrumento e recebeu em Viena o selo de aprovação da nobreza e passou a contar com o apoio irrestrito da $A M Z$ cujos donos começavam a publicar suas obras. Em oposição à "aderência a convenções composicionais externas", sua obra se destaca por sua "unidade estética interna" (DENORA, p.182). Os críticos da AMZ passam a utilizar termos como "em seus próprios termos" ou como um objeto que "em si mesmo faz sentido". Mais uma vez aqui, o que importa, para nós do século XXI, é o surgimento da concepção de uma peça musical independente de seu contexto social, que criou, a partir do romantismo a "torre-de-marfim" que enclausura a obra numa redoma inascessivel. Pioneiro nas táticas empreendedoras no campo musical, sua obra foi 0 divisor de águas de um público, cuja fração diletante seria colocada à margem do processo.

\section{1 - Beethoven e os recursos de autoridade cultural}

"A história do sucesso de Beethoven é assim a história da criação de uma cultura, a formação e implementação de instrumentos e dispositivos através dos quais uma imagem de Beethoven como talento extraordinário pôde ser transmitida para várias audiências" (DENORA, p.187-188). "Em retrospecto, o talento de Beethoven é visto de modo a destacar sua 'extraordinária' qualidade. Mas no momento de sua construção, tudo foi acumulado gradualmente, praticamente, e ordinariamente, no tempo e no espaço, nem predestinadamente nem planejado em sua totalidade" (DENORA, p.188).

Dizer que seu sucesso é produto apenas de sua obra, segundo DeNora, seria falacioso, na medida em que se desprezaria a interação de sua música e o contexto de recepção. Seria como ver através de um telescópio, tomando como verdade pronta 0 ato de que 0 passado conduziria invitavelmente às circunstâncias presentes, numa empobrecida concepção de História (DENORA, p.188). Ao longo do livro, DeNora se propôs a demonstrar o quanto o sucesso de Beethoven é também tributário de um "processo colaborativo de mobilização de recursos, dispositivos de apresentação e atividades práticas que produziram sua autoridade cultural" (DENORA, p.189).

Nos anos 1790, a originalidade musical ainda não estava automaticamente relacionada a valor em música, até muito pelo contrário, o compositor que não se adequasse aos padrões tradicionais e aos afetos compartilhados poderia ser considerado um outsider, não fosse, nesse caso, todo o background social e os interesses envolvidos.

\section{2 - Conclusão}

Em que pesem as críticas presentes nas resenhas, o que importa neste trabalho são as implicações de um modelo de construção da genialidade que compartilhamos até hoje e que se tornou inoperante num sistema de vale-tudo da criação musical, herdeira das concepções românticas das quais Beethoven e seu círculo foram os fundadores, produzindo o que MARTINS (1999, p.96) chamou de "máquina de imortalidade". RAYNOR (p.410) já apontava em $1972^{29}$ :

A música havia passado da fase em que era uma necessidade social para se converter em prazer remoto e esotérico tonitruado por imensas orquestras ou dada por executantes e cantores prodigiosos. Tornou-se cada vez mais o prazer de uma elite requintada do que uma comunicação imediata entre homens e mulheres. Não demorou muito e o compositor ambicioso descobriu que fazer música de dança e entretenimento fácil estava abaixo de sua dignidade, e uma sociedade dividida teve de se arranjar com uma arte dividida; a necessidade social era atendida, não por Brahms e Wagner, Verdi e Bruckner, mas pela familia Strauss e suas valsas e polcas; e os Strauss eram, afinal, grandes mestres no seu estilo. Dentro em breve, nada com o ritmo certo haveria de satisfazer a necesssidade social da música.

Para vislumbrar o quanto perdemos hoje em dia pela busca incessante de originalidade, é oportuno lembrar um poema de Millôr FERNANDES (1984, p.48):

Tão pra frente, tão pra frente

Que nunca fez como a gente

Que sempre chega atrasado

Mas uma vez, desesperado,

Viu que tinha exagerado,

No passar pra trás, no tempo,

Mesmo os mais avangardantes;

Pois saiu de casa um dia

E voltou um dia antes. 


\section{Referências}

ANDERSON, Robert. Review: Constructing Genius. Source: The Musical Times, v. 139, n. 1864 (Autumn, 1998), p. 60-61. Published by: Musical Times Publications Ltd. http://www.jstor.org/stable/1003472 (acesso em 02/02/2012).

BORN, Geogina e HESMONDALGH, David. Western music and its others. Los Angeles, University of California Press, 2000 BOWEN, José. The Value of Beethoven. Beethoven Hero by Scott Burnham; Beethoven and the Construction of Genius: Musical Politics in Vienna, 1792-1803 by Tia DeNora. Review by: José A. BOWEN, page 91 of 91-99. Disponível em http://www.jstor.org/stable/746794 (acesso em 02/02/2012).

CORRÊA, Paula da Cunha. Harmonia. São Paulo, Humanitas/FFLCH/USP, 2003

DENORA, Tia. Beethoven and the construction of Genius. Musical Politics in Vienna, 1792-1803. London: University of California Press, 1995

DUBAL, 1999. David. Conversas com João Carlos Martins. São Paulo: Editora Green Forest do Brasil, 1999

EINSTEIN, Alfred. Mozart: his character, his work. London: Grafton Books, 1971

ELIAS, Norbert. Mozart: sociología de un genio. Barcelona: Ediciones 62 S.A., 1991

FERNANDES, Millôr. Poemas. Porto Alegre: L\&PM, 1984

FLÉCHET, Anaïs. Villa-Lobos à Paris: un écho musical du Brésil. Paris: L'Hartmattan, 2004

GROVE Music Online disponivel em http://www.oxfordmusiconline.com/subscriber/article/grove/music/40258pg3\#S40258.3 (acesso em 31/01/2012)

FRANCFORT, Didier. In La provocation, Vingtième Siècle. Revue d'histoire 1/2007 ( $n^{0}$ 93), p. 3-5. Disponível em http:// www.cairn.info/article.php?ID_REVUE=VINGCID_NUMPUBLIE=VIN_093\&ID_ARTICLE=VING_093_0003 (acesso em 13/01/2011).

GUÉRIOS, Paulo Renato. Heitor Villa-Lobos: o caminho sinuoso da predestinação. Rio de Janeiro: FGV, 2003

HANSON Alice M. In Notes, Second Series,v. 53, n. 3 (Mar., 1997), p.798-800. Published by: Music Library Association. Disponivel em http://www.jstor.org/stable/899735 (acesso em 02/02/2012).

KINDERMAN, William. "Beethoven and the Construction of Genius: Musical Politics in Vienna, 1792-1803" (Review). In The Historian, January 1, 2000. Disponivel em http://www.highbeam.com/doc/1G1-60578692.html (acesso em 31/01/2012)

KNITTEL, K. M. "Beethoven and the Construction of Genius: Musical Politics in Vienna, 1792-1803." Beethoven Forum (2000): 177. Academic OneFile. Web. 28 Dec. 2010. Disponível em http://find.galegroup.com/gtx/infomark. do? ?contentSet=IAC-Documents\&type $=$ retrieve\&tabID=T001 $\&$ prodld $=A 0 N E C t d o c l d=A 70493463 \&$ source $=$ galectsrc prod $=$ AONECtuserGroupName $=$ capes 2 Ctversion $=1.0$

RAYNOR, Henry. História social da música. Rio de Janeiro: Zahar Editores, 1981

RICCIARDI, Rubens Russomano. Manuel Dias de Oliveira, Um compositor brasileiro dos tempos coloniais - partituras e documentos (Tese). São Paulo: ECA/USP, 2000

ROSEN, Charles. Beethoven's Genius: An Exchange APRIL 10, 1997 Tia DeNora, reply by Charles Rosen. Disponível em http://www.nybooks.com/articles/archives/1997/apr/10/beethovens-genius-an-exchange/ (acesso em 02/02/2012).

ROSEN, Charles. Did Beethoven Have All the Luck? New Yor Review of books, November 14, 1996. Disponivel em http:// www.nybooks.com/articles/archives/1996/nov/14/did-beethoven-have-all-the-luck/?pagination=false (acesso em 02/02/2012).

SOLOMON, Maynard. Beethoven. Rio de Janeiro: Zahar, 1987

TRIG0, Luciano. A grande feira: uma reação ao vale-tudo na arte contemporânea. Rio de Janeiro: Civilização Brasileira, 2009

Notas

1 Não há aqui qualquer intenção hegemônica: o termo "música séria" é utilizado para designar a nova ideologia que começava a se fixar naquele contexto.

2 ROSEN (1996) empreende uma discussão com a autora muito provavelmente em reação às p.123-124, onde ela diz sobre sua análise da Hammerklavier que "statements such as this, which attempts to asses stylistic 'turning points' in a composer's body of works, are problematic from a sociological point of view because music analysis is formulated, and only makes sense within, specific historical and cultural contexts" (as traduções citadas no corpo do texto são minhas).

3 This book is aimed at the serious students of Beethoven biography, those well versed in the personalities and issues at the end of the eighteenth century, and those acquainted with scholarly approaches to cultural history.

4 She offers her book as a corrective to existing scholarship, "where so much of the field of Beethoven studies is occupied by hagiography," and she opposes accounts "that isolate the quality of Beethoven's works as the cause of his recognition". e que DeNora, who gives too little attention generally to the German-language literature. 
5 We also seldom think of how much we lose in treating Beethoven not as a person but as Beethoven. Perhaps the most valuable aspect of DeNora's book is the glimpse it gives of the young Beethoven: not as a titan coming to conquer the meek Viennese, but rather as an ambitious yet cautious young man, arriving in a distant city, carefully learning the complexities of Viennese society, and learning, too, which social and musical conventions could be stretched, tested, or even broken.

6 If one is going to examine Beethoven as a cultural icon, a discussion of the music can have only one of two purposes: either to reify the myth or to debunk it. But if the goal of the project is neither of those two things, then avoiding the music may be one way of achieving the distance necessary to write a historical critique.

7 Reception history is the study of what other issues may have influenced critics to view a piece in a particular way (...)The music is thus an entry point for examining cultural context. (...).

8 Is she then claiming that Beethoven's music is not transcendent? No. But she is suggesting that to make such a claim is to forgo many other possibilities of hearing and writing history.

9 Put more radically, we are asked to question to what extent our assessment of Beethoven's greatness may be chalked up simply to imperialist history: the propaganda of the victors.

10 The shared thesis is not merely that Beethoven has become a highly valued or authoritative figure (that would hardly require two books) but that many of our cherished musical values-unity, economy, logic, originality, simplicity, complexity, spirituality, periodization, elitism, universality, seriousness, and even the work concept arose because we have accepted Beethoven's music as the standard.

11 An examination of past and present writing about music uncovers not only the range of values implic- itly linked to Beethoven but also the tendency to compare all subsequent composers to Beethoven.

12 The drive to make Beethoven the measure of all things musical is so strong that we persist in doing so even when it threatens the status of other cherished composers.

13 It is precisely during Beethoven's life that new ideas about the identity of musical works, the musical canon, instrumental music, poetic content, and musical seriousness come to the fore.

14 It may be as difficult to hear with the ears of another culture as it is to hear with the ears of another era. Still, we could reconsider the ways in which we teach listening, which might, at least, open our own ears to additional possibilities. Such a project might actually be the principal legacy of this reevaluation of Beethoven.

15 Statements such as this, which attempts to asses stylistic 'turning points' in a composer's body of works, are problematic from a sociological point of view because music analysis is formulated, and only makes sense within, specific historical and cultural contexts.

16 The history of music is an interaction of individual talent, social pressures, and the musical system already in place. The most stable of these factors is, in fact, the musical system. Ignoring it completely, as DeNora does, vitiates every generalization.

17 The greatest disappointment in DeNora's account is the lack of any historical consideration of the idea of greatness in music or the other arts. The late eighteenth century does not mark the first appearance of the concept of the temperamental genius in music. The Netherlandish composers, including Johannes Ockeghem, Pierre de la Rue, and Josquin des Prés, at the end of the fifteenth century had already developed that kind of international prestige, which made them sought after by Italian courts, and they had also demonstrated their importance by an extremely complex and learned style. Moreover, this style was not merely a demonstration of craft: we have only to read the account of an early sixteenth-century critic like Glarean to see the enormous emotional impact of the music of Josquin, who reduced his listeners to tears, and who, furthermore, was known for his arrogant and temperamental refusal to write music when commissioned except when he felt like it. The basic model of the temperamental genius, however, was to be found in the visual arts, with Michelangelo. Beethoven's persona, the figure he presented to the world of a difficult, irascible nonconformist, is clearly an imitation of the mythical paradigm of the temperamental genius refusing to bow to the authority of pope or aristocrat that Michelangelo supplied for the centuries that followed him. This would suggest that the relation of a high classical art and the artist as genius to an aristocratic society is a very complex one, in which the artist's genius is a trophy for the court that hires him but also a protest against, and an undermining of, the aristocratic authority that finances the art.

18 The gap between trivial and serious music was established and enforced in Vienna by the musicians themselves. The first musicians' union in Vienna, formed in the early 1780s, explicitly denied membership to performers of dance music. The gradual increase in the seriousness of nonliturgical music at this time was a natural result of the decline of church and court patronage, and the necessity of guaranteeing the musicians' livelihood in other ways and increasing their social standing.

19 [van Swieten] whose policies towards the division of Poland are less commendable than his search for a canon of musical greatness that was of such service to Mozart (who among other Handel works redid only one oratorio, Messiah), Haydn and Beethoven.

20 Mozart took part in van Swieten's Sunday noontime concerts (where participants sang Bach choral music, accompanied by Mozart on piano), and he orchestrated the four Händel oratorios, under instructions from van Swieten to "clothe Händel so solemny and so tastefully that he pleases th modish fop on the hand and on the other still shows himself in his sublimity".

21 Grove online: Disponivel em <http://www.oxfordmusiconline.com/subscriber/article/grove/music/40258pg3\#S40258.3. (acesso em 31/01/2012).

22 ..."PLATÃo (Leis 669b-70) bane a música puramente instrumental por uma série de razões, e uma delas ilumina essa questão: diz ele que o juizes têm dificuldade em avaliar o caráter de uma música quando ela não tem letra. A música instrumental é também criticada por exigir do músico uma especialização, impedindo a participação do cidadão comum" (...). In CORRÊÂ, 2003, p.51-52.

23 Conforme a tabela 3 da página 31, "Performances of works by Vienna's most frequently performed composers, 1791-1810".

24 Se os nossos árcades mereceram obras pseudocompletas impressas por Garnier e reproduzidas frequentemente sem mais exame ou crítica, a maioria dos autores brasileiros dos tempos coloniais nunca teve uma segunda edição sequer. Toda a enorme produção de oratória religiosa dos séculos XVII e XVIII, tão importante e tão caracteristica da cultura barroca, nunca foi reimpressa, salvo um ou outro sermão... Chego às vezes a pensar que o desequilibrio notado na maioria das histórias da literatura brasileira, em favor da poesia, e da poesia da "Escola Mineira", provém, em grande parte, da facilidade com que se encontravam edições recentes (copiadas por Garnier) desses maviosos vates. Parece-me que a maioria dos que escreveram sobre nosso passado cultural não avaliaram, equitativamente, toda a variedade de gêneros de nossa produção intelectual (MORAES, 1969, apud RICCIARDI, 2000, p.46).

25 Nos mesmo moldes propostos por BORN e HESMOLDALGH (orgs.) et al. (2000).

26 (1) Beethoven's music was increasingly perceived as thicker textured, (2) the piano music was discussed as less inclined to scale patterns, (3) the melodies were perceived as more ambiguously structured and less periodic, (4) the harmonies are perceived as more adventurous and ambiguous, (5) the dynamic range was perceived as greater (with sudden changes and sforzandos more common), and (6) some of the compositions were noted as lenghtier than thoseof his predecessors and contemporaries.

27 Da mesma maneira, FRANCFORT (2007) discute a provocação e as "estratégias conscientes de ocupação de um campo cultural". 
28 Sobre o vale-tudo na arte contemporânea, ver TRIGO, 2009. 0 que se critica aqui não é a obra de Beethoven, mas uma prática de fabricação de obras-primas que se tornou o padrão das produções atuais. Quem é afinal um compositor erudito contemporâneo senão alguém que já escreve para uma suposta posteridade, desprezando o contexto de recepção e a crítica, num "processo tautológico de construção das bases de percepção do talento e do sucesso" (DENORA, p. 140).

29 Publicado no Brasil em 1981.

Marcos Câmara de Castro é Professor Doutor no Departamento de Música da Faculdade de Filosofia, Ciências e Letras de Ribeirão Preto (SP). Graduado em composição, tem mestrado e doutorado sobre o compositor mineiro Fructuoso Vianna (1896-1976). Na área de regência e canto coral, vem revisando criticamente a bibliografia e editando o Cancioneiro Coral Brasileiro. Criou em 2008 a Orquestra Universitária USP/RP: ação e reflexão na prática orquestral. Essas ações estão reunidas em sua principal linha de pesquisa: Etnografia da música erudita contemporânea: criação e performance. 